Original research article

Food Quality and Functionality Section

\title{
Physicochemical Properties of Biscuits Enriched with Horseradish (Armoracia rusticana L.) Products and Bioaccessibility of Phenolics after Simulated Human Digestion
}

\author{
Lolita Tomsone* ${ }^{\circledR}$, Ruta Galoburda ${ }^{\circledR}$, Zanda Kruma ${ }^{\circledR}$, Kristine Majore ${ }^{\circledR}$ \\ Department of Food Technology, Faculty of Food Technology, \\ Latvia University of Life Sciences and Technologies, Rigas street 22, Jelgava, Latvia
}

Key words: horseradish, pomace, microencapsulated juice, total phenolic content, radical scavenging activity, bioaccessibility

\begin{abstract}
Health-conscious consumers are interested in products with an increased bioactive compound content. The nutritional quality is considered both as a stability and bioaccessibility concern. The aim of this study was to investigate the effect of horseradish products (horseradish root pomace, horseradish leaf pomace, microencapsulated horseradish root and leaf juice) on the physicochemical properties of biscuits, as well as to assess in vitro bioavailability and activity of phenolics. The bioactive compounds and antioxidant activity of horseradish products, which were used to replace the flour in biscuit dough, were analysed. Physicochemical parameters ( $\mathrm{pH}$, water activity, colour, phenolic compound contents, and antioxidant activities) were determined for the biscuits. Horseradish products compared to other cruciferous vegetables have a high content of phenolic compounds, as well as high antioxidant activity. Higher levels of bioactive compounds were found in microencapsulated horseradish leaf juice, compared to the other horseradish products used in the study. Enriched biscuits had a significantly higher total phenolic content (TPC) and antioxidant activity, compared to the control. After 180-day storage, TPC of biscuits with horseradish root products did not change significantly but in biscuits with horseradish leaf products it decreased by $27-29 \%$. The bioaccessibility index of phenolic compounds after in vitro digestion of enriched biscuits ranged between 2.19 and 2.99 . Microencapsulated horseradish leaf juice was more effective in enriching biscuits with bioactive compounds. The developed biscuits enriched with horseradish products could meet consumer expectations for healthy, functional food.
\end{abstract}

\section{INTRODUCTION}

No matter how healthy people want to eat, they also like to have some snacks, treats, and fast carbohydrates, such as biscuits. To make these snacks healthier, it is possible to use biologically active compounds from plants of natural origin in their preparation. Scientists around the world have already conducted studies on the addition of various plant products, by-products of food production, as well as plant extracts to foods, improving their nutritional value as well as biological value. For example, it has been possible to significantly increase the content of phenolic compounds and increase the antioxidant activity of bread with the addition of sweet-lupines [Villarino et al., 2014], rice bran [Irakli et al., 2015], cumin and caraway seeds and by-products [Sayed-Ahmad et al., 2018b], chia seeds and cakes [Sayed-Ahmad et al., 2018a], pasta with mango peel powder [Ajila et al., 2010], Hibiscus sabdariffa L. calyxes' residue [Ahmed \& Abozed, 2015], and biscuit with grape marc extract [Pasqualone et al., 2014]. As each plant has a specific profile of individual phenolic compounds, their behaviour and efficiency in food matrices also differ; therefore in-depth research of new sources is advisable.

Plants are rich in many biologically active compounds, such as phenolics (phenolic acids and flavonoids), and es-

\footnotetext{
* Corresponding Author: E-mail: Iolita.tomsone@Ilu.Iv (L. Tomsone)
}

sential oils, which possess various antioxidant properties [Naczk \& Shahidi, 2004]. Therefore, local plants specific to each region, but not widely used, are also sought and identified. Horseradish (Armoracia rusticana L.) is a plant growing in temperate latitudes that does not require special growing conditions, and a previous study [Tomsone, 2015] has shown that these plants contain high amounts of biologically active compounds such as phenolic compounds with antioxidant properties. It was found that total phenolic content (TPC) of horseradish leaves was 711-5406 mg GAE/100 g dry matter (DM), but TPC of roots was on average 7-10 times lower. Other studies showed a smaller difference in TPC between leaves and roots, i.e., 256-385 mg GAE/100 g DM and 174-289 mg GAE/100 g DM, respectively [Calabrone et al., 2015]. These plants have long been used for medicinal purposes with a wide range of applications for the treatment of various diseases using both roots and leaves [Agneta et al., 2013]. Although horseradish roots have a greater culinary value, horseradish leaves can also be used for food purposes. Like other cruciferous plants, besides phenolic compounds [Prieto et al., 2019], horseradish is rich in volatile sulphur-containing compounds - glucosinolates [Kloucek et al., 2012], and enzymes such as peroxidase and myrosinase [Belitz et al., 2009; Mokdad et al., 2009].

The high content of biologically active substances in certain food ingredients does not always ensure high bioacces- 
sibility and bioavailability during digestion. Bioavailability, defined as the amount of compounds available for absorption, can depend on a number of factors. These factors are affected by the chemical structure of compounds caused by glycosylation, esterification and polymerization [Alminger et al., 2014; Gayoso et al., 2018]. The raw materials of the plant kingdom consist of many compounds, which could be unstable in the aggressive environment of the stomach. They can be stabilised using modern technologies. One of such solutions is microencapsulation. It is a physical solution to prevent premature degradation of these substances, where the microcapsule wall acts as a physical protective barrier to chemical compounds.

The aim of this study was to investigate the effect of horseradish root pomace, horseradish leaf pomace, microencapsulated horseradish root and leaf juice on the physicochemical properties of biscuits, as well as to assess in vitro bioavailability and activity of phenolics.

\section{MATERIALS AND METHODS}

\section{Horseradish products}

Horseradish (A. rusticana L.) was harvested in Latvia (latitude $56^{\circ} 39^{\prime} \mathrm{N}$, longitude $23^{\circ} 44^{\prime} \mathrm{E}$ ), washed, cut in $5 \mathrm{~cm}$ long pieces. Horseradish leaves and roots were packed in polyethylene bags (approximately $0.5 \mathrm{~kg}$ each, in total $50 \mathrm{~kg}$ roots and $25 \mathrm{~kg}$ leaves) and frozen at $-18^{\circ} \mathrm{C}$. Horseradish root and leaf juice was obtained by grinding the frozen sample, and then extracting in a basket press. Juice was microencapsulated in a Mini Spray Dryer B-290 (Büchi, Flawil, Switzerland) using maltodextrin as a wall material at the core-to-wall ratio of 50:50 [Tomsone, 2020b]. Horseradish root and leaf pomace was dried in a Musson-1 microwave-vacuum drier (Ingredient, St. Petersburg, Russia) as described by Tomsone et al. [2020a].

\section{Biscuit preparation}

Biscuits were prepared according to the formulation described in Table 1, and the calculation of the required amount of horseradish product to be added was based on the TPC in each product. The traditional recipe of butter biscuit dough was selected for a control. Horseradish products were used to enrich biscuits with phenolic compounds.

All ingredients were mixed using a Varimixer AR10 mixer (Wodschow \& Co., Brondby, Denmark) for $\pm 10 \mathrm{~min}$. The dough was allowed to rest for $\pm 10 \mathrm{~min}$, and then rolled in a $0.7 \mathrm{~cm}$ thick sheet. Circles of $4.5 \mathrm{~cm}$ in diameter were then cut and were further divided into four equal segments. Biscuits were baked using the silicon baking sheet at $200 \pm 5^{\circ} \mathrm{C}$ for $\pm 10 \mathrm{~min}$ in a rotary oven (Sveba Dahlen, Fristad, Sweden). Two batches (each $800 \mathrm{~g}$ ) of biscuits were baked for each formulation and tempered to room temperature $22 \pm 2^{\circ} \mathrm{C}$ within $1 \mathrm{~h}$. Biscuits were then stored in cardboard boxes at room temperature in the dark at $60 \pm 5 \%$ relative air humidity and analysed twice - on the next day after baking (further referred to as: before storage) and after 180 days storage (further referred to as: after storage). Ten biscuits were randomly selected from the batch, crushed and used as the average sample for further analysis.

\section{Reagents}

Gallic acid, Folin-Ciocalteu reagent, and 2,2-diphenyl1-picrylhydrazyl radical $\left(\mathrm{DPPH}^{*}\right)$ were purchased from Sigma-Aldrich (Buchs, Switzerland). All other chemicals were obtained from Acros Organics (Belgium, WI, USA).

\section{Spectrophotometric assays of the total phenolic content and antioxidant activity}

\section{Extraction procedure}

The extraction of phenolic compounds from horseradish root and leaf pomace was done according to Tomsone et al. [2020a]. Briefly, dried pomace was ground and twice extracted using acetone in an ultrasonic bath and then re-extracted with ethanol/water $(80: 20, v / v)$. Extraction was completed in triplicate for each type of pomace.

For the spectrophotometric analysis of microencapsulated horseradish root and horseradish leaf juice, $0.1 \mathrm{~g}$ of powder was dissolved in $100 \mathrm{~mL}$ of distilled water and stirred for $20 \mathrm{~min}$ on a magnetic stirrer (magnet size $4.0 \times 0.5 \mathrm{~cm}$ ) at $700 \mathrm{rpm}$. Three extracts were prepared for each type of microcapsules.

For biscuit extraction, $2.5 \mathrm{~g}$ of crushed biscuits were suspended in $10 \mathrm{~mL}$ of an ethanol/water mixture $(80: 20, v / v)$ in a glass flask. The extraction was completed at $20 \pm 1^{\circ} \mathrm{C}$ in an ultrasonic bath YJ5120-1 (Oubo Dental, St. Louis, MO, USA) for $30 \mathrm{~min}$ at $35 \mathrm{kHz}$. The clear top layer of the extract was decanted and centrifuged using a CM-6MT centrifuge (Elmi Ltd., Riga, Latvia) for $5 \mathrm{~min}$ at 3,500 rpm. The supernatant was collected in a $25-\mathrm{mL}$ graduated flask. Biscuit sediment was re-extracted with $10 \mathrm{~mL}$ of a fresh solvent and treat-

TABLE 1. Formulation of biscuit doughs with different horseradish products.

\begin{tabular}{|c|c|c|c|c|c|}
\hline \multirow{2}{*}{ Ingredients } & \multicolumn{5}{|c|}{ Samples } \\
\hline & $\mathrm{C}$ & B_HRP & B_HLP & B_HRM & B_HLM \\
\hline \multicolumn{6}{|l|}{$\begin{array}{l}\text { Flour and horseradish } \\
\text { products, incl. }\end{array}$} \\
\hline flour (g) & 500 & 487.50 & 497.10 & 492.10 & 499.20 \\
\hline $\begin{array}{l}\text { dried horseradish } \\
\text { root pomace }(\mathrm{g})\end{array}$ & - & 12.50 & - & - & - \\
\hline $\begin{array}{l}\text { dried horseradish } \\
\text { leaf pomace }(\mathrm{g})\end{array}$ & - & - & 2.90 & - & - \\
\hline $\begin{array}{l}\text { horseradish root } \\
\text { microcapsules (g) }\end{array}$ & - & - & - & 7.90 & - \\
\hline $\begin{array}{l}\text { horseradish leaf } \\
\text { microcapsules (g) }\end{array}$ & - & - & - & - & 0.80 \\
\hline Butter (g) & 270 & 270 & 270 & 270 & 270 \\
\hline Sugar (g) & 125 & 125 & 125 & 125 & 125 \\
\hline Egg mass (g) & 50 & 50 & 50 & 50 & 50 \\
\hline Salt (g) & 5 & 5 & 5 & 5 & 5 \\
\hline Baking powder (g) & 3 & 3 & 3 & 3 & 3 \\
\hline
\end{tabular}

Abbreviations: C: control; B_HRP: biscuits with horseradish root pomace powder; B_HLP: biscuits with horseradish leaf pomace powder; B_HRM: biscuits with horseradish root juice microcapsules; B_HLM: biscuits with horseradish leaf juice microcapsules. 
ed in an ultrasonic bath for an additional $10 \mathrm{~min}$. The top layer was decanted and centrifuged for 5 min. Both supernatants were combined in a $25-\mathrm{mL}$ graduated flask and filled with solvent till the mark. Extraction was completed in triplicate for each sample.

\section{Spectrophotometric analysis}

All spectrophotometric analyses were performed using a JENWAY 6300 spectrophotometer (Barloworld Scientific Ltd., Staffordshire, UK) and were used according to the procedure described by Tomsone et al. [2020a].

The total phenolic content (TPC) was determined according to the Folin-Ciocalteu spectrophotometric assay described by Singleton et al. [1999]. Calculations were done using a standard curve of a gallic acid solution in water, and results were expressed as mg gallic acid equivalents (GAE) per $100 \mathrm{~g}$ of DM. Each extract was analysed in triplicate.

$\mathrm{DPPH}^{*}$ scavenging activity was determined according to the method described by $\mathrm{Yu}$ et al. [2003]. The 2,2'-azino-bis(3-ethylbenz-thiazoline-6-sulfonic) acid (ABTS) was used to determine $\mathrm{ABTS}^{\cdot}{ }^{+}$scavenging activity according to Re et al. [1999] procedure. Calculations were done using a standard curve, and results were expressed as mmol 6-hydroxy-2,5,7,8-tetramethylchroman-2-carboxylic acid (Trolox) equivalents per $100 \mathrm{~g}$ DM. Each extract was analysed in triplicate.

\section{Determination of individual phenolic compounds and organic acids}

Individual phenolics and organic acids were determined by HPLC as described by Tomsone et al. [2020a]. Briefly, $1 \mathrm{~N} \mathrm{HCl} /$ ethanol/distilled water $(1: 80: 19, v / v / v)$ was used for phenolics extraction in an ultrasonic bath YJ5120-1 (Oubo Dental) at $35 \mathrm{kHz}$ and $20 \pm 1^{\circ} \mathrm{C}$ for $10 \mathrm{~min}$. The supernatants obtained after centrifugation were then separated and quantified using a Prominence LC-20AD HPLC system (Shimadzu, Canby, OR, USA) with a photodiode array detector SPD M20A (Shimadzu, Kyoto, Japan). For determination of organic acids, samples were extracted with a solution of metaphosphoric acid in distilled water ( $\mathrm{pH} 3.0$ ), using a magnetic stirrer. The analytical C18 column (Perkin Elmer, $4.6 \mathrm{~mm} \times 250 \mathrm{~mm}, 5 \mathrm{~mm}$ ) and detection at a wavelength of $210 \mathrm{~nm}$ were used. The total organic acids were calculated as a sum of oxalic, tartaric, quinic, malic, malonic, ascorbic, citric, fumaric, and succinic acids. Each extract was analysed in triplicate.

\section{Determination of moisture content, $\mathrm{pH}$, and water activity}

Moisture content in the horseradish products (dried horseradish root pomace, dried horseradish leaf pomace, microencapsulated horseradish juice, and microencapsulated horseradish leaf juice) and biscuits was determined according to the International Organization for Standardization (ISO) 6496 standard [ISO, 1999], which was used for the expression of results in dry matter. Each batch was analysed in triplicate.

The water activity $\left(\mathrm{a}_{\mathrm{w}}\right)$ was measured directly at $25^{\circ} \mathrm{C}$ using the Novasina Thermoconstanter model Labswift-a (Novasina AG, Lachen, Switzerland). Each reading was completed according to the manufacturer's instructions and done in triplicate for each batch.
The $\mathrm{pH}$ value of the samples was measured according to Association of Official Analytical Chemists (AOAC) method No. 943.02 [AOAC, 2020] with some modifications. The biscuit sample ( $5 \mathrm{~g}$ ) was weighed into an Erlenmeyer flask and $50 \mathrm{~mL}$ of distilled $\mathrm{H}_{2} \mathrm{O}$ was added. The suspension was prepared by mixing for $10 \mathrm{~min}$ at $25^{\circ} \mathrm{C}$. Then, the $\mathrm{pH}$ was measured using a Jenway-3505 pH-meter (Barloworld Scientific Ltd., Dunmow, Essex, UK) with a glass electrode standardized by buffer solutions of $\mathrm{pH} 4$ and $\mathrm{pH} 7$, both at $25^{\circ} \mathrm{C}$. Each batch was analysed in triplicate.

\section{Colour evaluation}

Colour analyses were performed using a ColorTec-PCM instrument (Accuracy Microsensors, Inc., Pittsford, New York, USA), using the CIE L* $a^{*} b^{*}$ colour space, where $L^{*}$ represents the sample's lightness in the range from 0 (black) to 100 (white), $a^{*}$ is the redness from green to red $\left(-a^{*}-+a^{*}\right)$, and $b^{*}$ is the yellowness from blue to yellow $\left(-b^{*}-+b^{*}\right)$. Each biscuit type was crushed and placed in a PE-LD ziplock bag (size $60 \times 75 \mathrm{~mm}$ ). The colour of each batch was measured on the bag surface in ten random places.

The total colour difference $(\Delta \mathrm{E})$ between the enriched biscuits and the butter biscuits without horseradish (control) on the day after baking and cooling was calculated using Equation (1):

$\Delta \mathrm{E}=\sqrt{\left(\mathrm{L}_{2}^{*}-\mathrm{L}_{1}^{*}\right)+\left(\mathrm{a}_{2}^{*}-\mathrm{a}_{1}^{*}\right)+\left(\mathrm{b}_{2}^{*}-\mathrm{b}_{1}^{*}\right)}$

where: $L_{2}{ }^{*}, a_{2}{ }^{*}$, and $b_{2}{ }^{*}$ - measured values of biscuit samples with horseradish products; and $\mathrm{L}_{1}{ }^{*}, \mathrm{a}_{1}{ }^{*}$, and $\mathrm{b}_{1}{ }^{*}$ - the values of butter biscuit samples (control).

The total colour difference $\left(\Delta \mathrm{E}_{\mathrm{t}}\right)$ between the samples after 180-day storage and the respective biscuits before storage was calculated using Equation (2):

$\Delta \mathrm{E}_{\mathrm{t}}=\sqrt{\left(\mathrm{L}_{\mathrm{t} 2}^{*}-\mathrm{L}_{\mathrm{t} 1}^{*}\right)+\left(\mathrm{a}_{\mathrm{t} 2}^{*}-\mathrm{a}_{\mathrm{t} 1}^{*}\right)+\left(\mathrm{b}_{\mathrm{t} 2}^{*}-\mathrm{b}_{\mathrm{t} 1}^{*}\right)^{2}}$

where: $\mathrm{L}_{\mathrm{t} 2}{ }^{*}, \mathrm{a}_{\mathrm{t} 2}{ }^{*}$, and $\mathrm{b}_{\mathrm{t} 2}{ }^{*}$ - measured values of biscuit samples after 180-day storage; and $\mathrm{L}_{\mathrm{t} 1}{ }^{*}, \mathrm{a}_{\mathrm{t} 1}{ }^{*}$, and $\mathrm{b}_{\mathrm{t} 1}{ }^{*}$ - measured values of the respective biscuit samples before storage.

Chroma $\left(\mathrm{C}^{*}\right)$ was calculated according to Equation (3), and hue angle (h) according to Equation (4) [Dag et al., 2017; Sant'Anna et al., 2013].

$\mathrm{C}_{\mathrm{ab}}{ }^{*}=\sqrt{\mathrm{a}^{* 2}+\mathrm{b}^{* 2}}$

$\mathrm{h}_{\mathrm{ab}}=\arctan \left(\mathrm{b}^{*} / \mathrm{a}^{*}\right)$

when $+\mathrm{a}^{*}$ and $+\mathrm{b}^{*}$ are in quadrant $\mathrm{I}$.

\section{In vitro digestion}

The digestibility of the products was assessed in a gastrointestinal tract (GIT) model - bioreactor, in which nutrient transit and digestibility were simulated. The GIT model used in the study (Multifors 2, INFORS-HT, Bottmingen-Basel, Switzerland) consisted of a $500 \mathrm{~mL}$ bioreactor tank in which the processes were controlled with the Iris 6 Pallalel Bio- 
process Control software (INFORS-HT, Bottmingen-Basel, Switzerland). The reactor was equipped with temperature and $\mathrm{pH}$ sensors, a magnetic stirrer, as well as pumps that controlled the rate of hydrochloric acid $(\mathrm{HCl})$ and sodium bicarbonate $\left(\mathrm{NaHCO}_{3}\right)$ addition. The temperature in the bioreactor was maintained at $37 \pm 0.11^{\circ} \mathrm{C}$ to implement the simulation process. During the process, continuous mixing was ensured at $120-250 \mathrm{rpm}$.

The digestibility of the products was simulated based on Minekus et al. [2014] enzymatic in vitro digestibility protocol. The product $(30 \mathrm{~g})$ was placed in a bioreactor connected to a temperature and $\mathrm{pH}$ sensor, $30 \mathrm{~mL}$ of simulated saliva fluid (SSF) were added, and the sample was kept at $37^{\circ} \mathrm{C}$ for $2 \mathrm{~min}$. The transition to the stomach was simulated by adding a simulated gastric fluid (SGF), pepsin, $\mathrm{CaCl}_{2}$, and distilled water into the bioreactor. Gastric acid secretion was simulated by adding $1 \mathrm{M} \mathrm{HCl}$ and adjusting the $\mathrm{pH}$ to $3.0 \pm 0.2$. Digestion in the stomach was simulated for $2 \mathrm{~h}$.

The stomach content was then neutralised to $\mathrm{pH} 7.0 \pm 0.2$ by $1 \mathrm{M} \mathrm{NaHCO}_{3}$ and a simulated intestinal fluid (SIF) containing a concentrated electrolyte solution, enzymes (trypsin, chymotrypsin, $\alpha$-amylase, lipase), bile salts, $\mathrm{CaCl}_{2}$, and distilled water was added, simulating the transit of gastric contents into the duodenum. Digestion in duodenum was simulated for $2 \mathrm{~h}$. The samples were frozen and stored at $-18 \pm 1^{\circ} \mathrm{C}$ till further analysis. Each batch was analysed in duplicate.

Prior to the analysis, the samples were defrosted and centrifuged for $30 \mathrm{~min}$. TPC and antioxidant activity ( $\mathrm{DPPH}^{\circ}$ and $\mathrm{ABTS}^{\cdot+}$ scavenging activity) were measured in the supernatant or the digested part. The bioaccessibility index (PAC) was calculated according to Equation (5) [Celep et al., 2017; Świeca et al., 2017]:

$\mathrm{PAC}=\mathrm{C}_{\mathrm{GE}} / \mathrm{C}_{\mathrm{BE}}$

where: $\mathrm{C}_{\mathrm{GE}}-$ the total phenolic content or antioxidant activity in the samples after gastrointestinal digestion; and $\mathrm{C}_{\mathrm{BE}}-$ the total phenolic content or antioxidant activity in the nondigested samples.

\section{Statistical analysis}

All experiments were performed with at least three replicates and the results are shown as mean \pm standard deviation. The analysis of variance (ANOVA) and Tukey's test or t-test were performed using SPSS version 17 (SPSS Inc., Chicago, IL, USA) to determine parameter differences between samples. The differences were considered significant at $p \leq 0.05$. Linear correlation analysis was performed to analyse the relationship between the variables tested.

\section{RESULTS AND DISCUSSION}

\section{Description of the horseradish products}

Horseradish products can be used as a source of antioxidants. An important group of the natural antioxidants, due to their reduction-oxidation potential, is phenolic compounds plant secondary metabolites. The horseradish products studied in the current research are also rich in phenolics.

The analysis of variance showed that the TPC, individual phenolic compounds, and antioxidant activity in horseradish products differed significantly (Table 2). TPC in the leaf pomace was four times higher, compared to the root pomace, but in the microencapsulated leaf juice it was 10 times higher, compared to the root juice. As previous studies reported, the horseradish leaves contained a higher amount of the phenolics, compared to roots [Tomsone, 2015]. In general, the microencapsulated horseradish leaf juice had a higher content of all the determined compounds, except for (+)-catechin (the highest content was detected in the horseradish root microcapsules). TPC ranged from $244.44 \mathrm{mg} / 100 \mathrm{~g} \mathrm{DM}$ of root pomace to $3730.38 \mathrm{mg} / 100 \mathrm{~g}$ DM of encapsulated leaf juice, showing potential especially for horseradish leaf products to improve the health value of biscuits with small quantities added.

TABLE 2. Phenolic compound and organic acid contents, and antioxidant activity of horseradish products.

\begin{tabular}{l|c|c|c|c}
\hline \multirow{2}{*}{ Parameters } & \multicolumn{2}{|c|}{ Pomace } & \multicolumn{2}{c}{ Microcapsules } \\
\cline { 2 - 5 } & $\begin{array}{c}\text { Root } \\
\text { HRP }\end{array}$ & $\begin{array}{c}\text { Leaf } \\
\text { HLP }\end{array}$ & $\begin{array}{c}\text { Root juice } \\
\text { HRM }\end{array}$ & $\begin{array}{c}\text { Leaf juice } \\
\text { HLM }\end{array}$ \\
\hline TPC $^{*}$ & $244.44 \pm 10.90^{\mathrm{d}}$ & $1028.57 \pm 27.64^{\mathrm{b}}$ & $376.64 \pm 8.05^{\mathrm{c}}$ & $3730.38 \pm 62.13^{\mathrm{a}}$ \\
DPPH• scavenging activity** $^{*}$ & $13.86 \pm 0.45^{\mathrm{d}}$ & $53.13 \pm 0.62^{\mathrm{c}}$ & $89.60 \pm 2.11^{\mathrm{b}}$ & $120.33 \pm 1.05^{\mathrm{a}}$ \\
ABTS $^{*}$ scavenging activity** & $23.64 \pm 0.79^{\mathrm{d}}$ & $298.84 \pm 7.96^{\mathrm{b}}$ & $120.47 \pm 3.10^{\mathrm{c}}$ & $631.32 \pm 13.56^{\mathrm{a}}$ \\
\hline$(+)-C a t e c h i *^{* * * *}$ & $6.96 \pm 0.32^{\mathrm{c}}$ & $2.39 \pm 0.10^{\mathrm{d}}$ & $42.04 \pm 1.15^{\mathrm{a}}$ & $9.90 \pm 0.43^{\mathrm{b}}$ \\
Sinapic acid*** & $0.71 \pm 0.04^{\mathrm{d}}$ & $1.53 \pm 0.08^{\mathrm{c}}$ & $11.67 \pm 0.54^{\mathrm{b}}$ & $324.92 \pm 11.25^{\mathrm{a}}$ \\
2-Hydroxycinnamic acid*** & $1.66 \pm 0.05^{\mathrm{d}}$ & $1.80 \pm 0.07^{\mathrm{c}}$ & $3.70 \pm 0.19^{\mathrm{b}}$ & $44.40 \pm 2.14^{\mathrm{a}}$ \\
Rutin*** & $37.77 \pm 1.73^{\mathrm{d}}$ & $220.23 \pm 1.68^{\mathrm{b}}$ & $75.46 \pm 2.77^{\mathrm{c}}$ & $2033.52 \pm 101.68^{\mathrm{a}}$ \\
\hline Total organic acids*** & $760.04 \pm 28.00^{\mathrm{c}}$ & $772.66 \pm 28.63^{\mathrm{c}}$ & $2725.91 \pm 106.30^{\mathrm{b}}$ & $6879.92 \pm 244.01^{\mathrm{a}}$ \\
\hline
\end{tabular}

All data are means \pm standard deviation $(n=9)$. a,b,c $\ldots$ - values with different superscripts in the same row are significantly different $(p \leq 0.05)$. ${ }^{*} \mathrm{mg}$ GAE (gallic acid equivalent)/100 g DM, ${ }^{* *} \mathrm{mmol}$ Trolox equivalent/100 g DM, ${ }^{* * *} \mathrm{mg} / 100 \mathrm{~g}$ DM. Abbreviations: HRP: horseradish root pomace powder; HLP: horseradish leaf pomace powder; HRM: horseradish root juice microcapsules; HLM: horseradish leaf juice microcapsules, TPC: total phenolic content, DM: dry matter. 
Among the individual phenolic compounds quantified in horseradish product samples, the highest content of rutin reached $2033.52 \mathrm{mg} / 100 \mathrm{~g}$ DM of horseradish juice microcapsules. Rutin has a wide range of bioactivities including antioxidant and anti-inflammatory ones, and therefore scientists are searching for its potential sources [Camponogara et al., 2020; Kherbache et al., 2020]. A similar content of rutin was found in dried aerial parts of buckwheat (2.66\%), but in extracts its content increased to $6.75 \%$ [Kim \& Lim, 2019]. The banana leaf extract also reached $5 \%$ of rutin [Yingyuen et al., 2020]. Results of the current study confirm that horseradish leaf juice can be a potential source of rutin.

Scientists have been testing the possibility of adding different phenolic-rich products to food, as each of the added products contains an individual and unique chemical profile, and compounds can react differently in each particular food matrix. Therefore, it is necessary to study the effect of phenolic compounds of horseradish on the food matrix. The obtained results allowed choosing the quantity of each horseradish product to be added, so that the same concentration of phenolic compounds would be added to each biscuit type based on the TPC.

Organic acids are important for plant metabolism and were found in all horseradish products analysed. Organic acids are closely related to the formation of phenolic compounds in plants, as they are part of the phenylpropanoid pathway biosynthesis. Horseradish leaf juice microcapsules (HLM) had the highest contents of organic acids among the studied products. There was a tendency that microencapsulated horseradish juice had 3-8 times higher content of organic acids, compared to the pomace. The main organic acids in all horseradish products were quinic, citric, fumaric, and succinic acids (data not shown).

\section{Biscuit characteristics}

Total phenolic content (TPC) and antioxidant activity in biscuits

The TPC values varied among the biscuit samples (Table 3). On the day after baking, the control biscuits $(\mathrm{C})$ had a significantly $(p \leq 0.05)$ lower TPC than the enriched biscuits. The addition of the horseradish products to biscuits increased their TPC by $21 \%$ (B_HRP) to $60 \%$ (B_HLM), compared to the control. Other researchers also succeeded in increasing the TPC of flour products by adding various plant materials rich in phenolics, such as rice bran by 200 to $400 \%$ [Irakli et al., 2015], and cumin seeds and by-products by 50-116\% [Sayed-Ahmad et al., 2018b]. The same amount of phenolic compounds provided by different horseradish products was added to the biscuits in the current research. However, the individual phenolic compound profiles of additives differed significantly. The horseradish leaf juice microcapsules had higher contents of rutin, sinapic acid, and 2-hydroxycinnamic acid, compared to the other horseradish products (Table 2). Possibly, some of the individual compounds were more susceptible to the increased temperature and moisture vaporization during baking, resulting in the loss of TPC.

During baking, the antioxidant activity, like TPC, also increased in the biscuits containing horseradish products (Table 3). Compared to the control, the DPPH ${ }^{\bullet}$ scavenging
TABLE 3. Total phenolic content (TPC) and antioxidant activity of biscuits enriched with horseradish products one day after baking and after 180-day storage.

\begin{tabular}{|c|c|c|c|}
\hline Samples & $\begin{array}{c}\text { Before } \\
\text { storage }\end{array}$ & $\begin{array}{c}\text { After } \\
\text { storage }\end{array}$ & $\begin{array}{c}\text { Changes } \\
\text { after storage }\end{array}$ \\
\hline \multicolumn{4}{|c|}{ TPC (mg GAE/100 g DM) } \\
\hline $\mathrm{C}$ & $14.82 \pm 0.71^{\mathrm{d}, \mathrm{A}}$ & $15.60 \pm 0.61^{\mathrm{b}, \mathrm{A}}$ & n.s. \\
\hline B_HRP & $17.96 \pm 0.36^{\mathrm{c}, \mathrm{A}}$ & $18.99 \pm 0.93^{\mathrm{a}, \mathrm{A}}$ & n.s. \\
\hline B_HLP & $23.15 \pm 0.93^{\mathrm{a}, \mathrm{A}}$ & $16.94 \pm 0.45^{\mathrm{b}, \mathrm{B}}$ & $27 \%(\downarrow)$ \\
\hline B_HRM & $21.74 \pm 0.43^{b, A}$ & $20.04 \pm 1.08^{\mathrm{a}, \mathrm{B}}$ & n.s. \\
\hline B_HLM & $23.75 \pm 0.43^{\mathrm{a}, \mathrm{A}}$ & $16.98 \pm 0.28^{\mathrm{b}, \mathrm{B}}$ & $29 \%(\downarrow)$ \\
\hline \multicolumn{4}{|c|}{ DPPH• scavenging activity (mmol TE/100 g DM) } \\
\hline $\mathrm{C}$ & $1.58 \pm 0.08^{\mathrm{c}, \mathrm{B}}$ & $2.11 \pm 0.03^{\mathrm{a}, \mathrm{A}}$ & $33 \%(\uparrow)$ \\
\hline B_HRP & $1.70 \pm 0.08^{\mathrm{b}, \mathrm{c}, \mathrm{B}}$ & $2.28 \pm 0.05^{\mathrm{a}, \mathrm{A}}$ & $34 \%(\uparrow)$ \\
\hline B_HLP & $1.86 \pm 0.06^{\mathrm{a}, \mathrm{b}, \mathrm{B}}$ & $2.18 \pm 0.01^{\mathrm{a}, \mathrm{A}}$ & $17 \%(\uparrow)$ \\
\hline B_HRM & $1.99 \pm 0.10^{\mathrm{a}, \mathrm{A}}$ & $2.14 \pm 0.12^{\mathrm{a}, \mathrm{A}}$ & n.s. \\
\hline B_HLM & $1.93 \pm 0.03^{\mathrm{a}, \mathrm{B}}$ & $2.23 \pm 0.08^{\mathrm{a}, \mathrm{A}}$ & $16 \%(\uparrow)$ \\
\hline \multicolumn{4}{|c|}{$\mathrm{ABTS}^{\bullet+}$ scavenging activity (mmol TE/100 g DM) } \\
\hline $\mathrm{C}$ & $1.06 \pm 0.05^{\mathrm{d}, \mathrm{A}}$ & $0.56 \pm 0.06^{\mathrm{e}, \mathrm{B}}$ & $47 \%(\downarrow)$ \\
\hline B_HRP & $1.25 \pm 0.06^{\mathrm{c}, \mathrm{A}}$ & $0.68 \pm 0.01^{\mathrm{d}, \mathrm{B}}$ & $46 \%(\downarrow)$ \\
\hline B_HLP & $1.80 \pm 0.08^{\mathrm{a}, \mathrm{b}, \mathrm{A}}$ & $1.32 \pm 0.04^{\mathrm{a}, \mathrm{B}}$ & $27 \%(\downarrow)$ \\
\hline B_HRM & $1.71 \pm 0.09^{\mathrm{b}, \mathrm{A}}$ & $1.15 \pm 0.05^{\mathrm{b}, \mathrm{B}}$ & $33 \%(\downarrow)$ \\
\hline B_HLM & $1.92 \pm 0.06^{\mathrm{a}, \mathrm{A}}$ & $1.10 \pm 0.03^{\mathrm{b}, \mathrm{c}, \mathrm{B}}$ & $43 \%(\downarrow)$ \\
\hline
\end{tabular}

All data are means \pm standard deviation $(n=18)$. ${ }^{\text {a,b,c }} \ldots$ - values with different superscripts in the same column for the same parameter are significantly different $(p \leq 0.05)$. ${ }^{\mathrm{A}, \mathrm{B}}$ - values with different superscripts in the same row are significantly different $(p \leq 0.05)$. Abbreviations: C: control; B HRP: biscuits with horseradish root pomace powder; B_HLP: biscuits with horseradish leaf pomace powder; B_HRM: biscuits with horseradish root juice microcapsules; B_HLM: biscuits with horseradish leaf juice microcapsules; DM: dry matter; n.s.: change is statistically insignificant $(p>0.05)$. $\uparrow:$ Percentage increase after 180-day storage. $\downarrow$ : Percentage decrease after 180-day storage.

activity increased by $7 \%$ (B_HRP) to 26\% (B_HRM), but the $\mathrm{ABTS}^{\cdot+}$ scavenging activity by $18 \%$ (B_HRP) to $81 \%$ (B_HLM).

The increase in the antioxidant activity has been reported when food production by-products were added to flour products. Mango peel powder increased antioxidant activity 3 to 22 times [Ajila et al., 2010], Hibiscus sabdariffa L. calyxes' residue by $18-140 \%$ [Ahmed \& Abozed, 2015], as well as cumin and caraway seeds and by-products [Sayed-Ahmad et al., 2018b], and chia seeds and cakes by $12-37 \%$ [Sayed-Ahmad et al., 2018a]. In this study, higher DPPH ${ }^{*}$ scavenging activity was found for the biscuits with horseradish root microcapsules (B_HRM), horseradish leaf microcapsules (B_HLM), and horseradish leaf pomace (B_HLP), while higher ABTS ${ }^{*}+$ scavenging activity for the biscuits with horseradish leaf microcapsules (B_HLM) and horseradish leaf pomace (B_HLP). It may be due to the different individual phenolic compound profiles of the horseradish products and the differences in an- 
tioxidant activity determination methods. The DPPH assay is fast and easy to use in measuring the ability of compounds to act as radical scavengers or hydrogen donors, and is therefore often used to determine the antioxidant potential of food products [Szawara-Nowak et al., 2016]. But still, the results could be interfered by different solubility of the compounds in alcohol and could depend on the chemical structure of the samples tested due to their different reaction kinetics with the radical. The ABTS assay, on the other hand, is another commonly used method for determining the antioxidant activity of foods containing a broader range of antioxidants, including hydrophilic and lipophilic compounds, but its results could also be affected by the chemical structure of compounds, $\mathrm{pH}$, and oxygen concentration in media.

The correlation between TPC and DPPH scavenging activity in the analysed biscuits before storage was strong $(r=0.869)$ and similar to these reported by Sayed-Ahmad et al. [2018b] and Moldovan et al. [2016]. The coefficient of correlation between TPC and $\mathrm{ABTS}^{\bullet+}$ scavenging activity was $\mathrm{r}=0.818$.

During storage, various biochemical reactions continue in the food. Antioxidants, including phenolic compounds, and their content change over time. It was observed that during storage, TPC did not change significantly $(p>0.05)$ in the biscuits with added horseradish root products (B_HRP and B_HRM) (Table 3). However, TPC decreased significantly $(p \leq 0.05)$ in the biscuits with the added horseradish leaf products (B_HLP and B_HLM) after 180-day storage. A similar decrease in TPC during storage was observed in rye ginger cakes [Zieliński et al., 2012], where TPC had decreased by $2-23 \%$ after storage. At the same time, TPC decreased significantly during storage of gluten-free rice-buckwheat biscuits [Sakač et al., 2016], and after 6 months of storage the decrease reached $26 \%$. The diversity of phenolic compounds in food matrixes and endogenous factors of food, such as $\mathrm{pH}$ and fat content, can affect the stability of phenolic compounds during storage [Ahmed \& Abozed, 2015; Alminger et al., 2014].

All analysed biscuits, except for B_HRM, showed a sig-

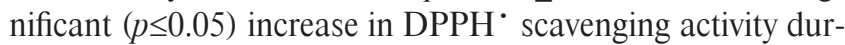
ing storage (Table 3 ). The largest changes were observed for the $\mathrm{C}$ and $\mathrm{B}$ _HRP samples. Changes in the antioxidant activity with $\mathrm{DPP} \mathrm{H}^{\cdot}$ could be explained by the development of Maillard reaction products, which have antioxidant properties. Zieliński et al. [2012] found that the content of Maillard reaction products increased by as much as $380 \%$ during storage of rye ginger cakes. The decrease in the TPC of the analysed biscuits during storage, and the increase in their $\mathrm{DPPH}^{*}$ scavenging activity can also be explained by the fact that the antiradical activity against $\mathrm{DPPH}^{\circ}$ may be provided by polar compounds other than phenolics.

The ABTS ${ }^{*}+$ scavenging activity of the experimental biscuits decreased until the end of the storage period (Table 3 ). The smallest changes were observed for B_HLP, but the largest ones for $\mathrm{C}$ and B_HRP samples. During storage, the ABTS ${ }^{*+}$ scavenging activity decreased similarly to TPC.

\section{The $\mathrm{pH}$ and water activity $\left(a_{w}\right)$ of biscuits}

Horseradish products contained organic acids, therefore adding them to biscuits lowered their $\mathrm{pH}$ (Table 4). The $\mathrm{pH}$
TABLE 4. $\mathrm{pH}$ and water activity of biscuits enriched with horseradish products one day after baking and after 180-day storage.

\begin{tabular}{l|c|c|c}
\hline Samples & $\begin{array}{c}\text { Before } \\
\text { storage }\end{array}$ & $\begin{array}{c}\text { After } \\
\text { storage }\end{array}$ & $\begin{array}{c}\text { Changes } \\
\text { after storage }\end{array}$ \\
\hline \multicolumn{4}{c}{$\mathrm{pH}$} \\
\hline C & $6.683 \pm 0.027^{\mathrm{a}, \mathrm{A}}$ & $6.711 \pm 0.004^{\mathrm{a}, \mathrm{A}}$ & n.s. \\
B_HRP & $6.476 \pm 0.009^{\mathrm{b}, \mathrm{A}}$ & $6.485 \pm 0.005^{\mathrm{b}, \mathrm{A}}$ & n.s. \\
B_HLP & $6.395 \pm 0.035^{\mathrm{c}, \mathrm{d}, \mathrm{A}}$ & $6.319 \pm 0.005^{\mathrm{d}, \mathrm{B}}$ & n.s. \\
B_HRM & $6.434 \pm 0.008^{\mathrm{c}, \mathrm{A}}$ & $6.380 \pm 0.005^{\mathrm{c}, \mathrm{B}}$ & n.s. \\
B_HLM & $6.397 \pm 0.028^{\mathrm{d}, \mathrm{A}}$ & $6.322 \pm 0.022^{\mathrm{d}, \mathrm{B}}$ & n.s. \\
\hline & & $\mathrm{a}$ \\
\hline C & $0.394 \pm 0.001^{\mathrm{a}, \mathrm{A}}$ & $0.385 \pm 0.001^{\mathrm{b}, \mathrm{B}}$ & $\mathrm{n} . \mathrm{s}$. \\
B_HRP & $0.259 \pm 0.001^{\mathrm{b}, \mathrm{B}}$ & $0.382 \pm 0.001^{\mathrm{d}, \mathrm{A}}$ & $47 \%(\uparrow)$ \\
B_HLP & $0.188 \pm 0.001^{\mathrm{d}, \mathrm{B}}$ & $0.387 \pm 0.001^{\mathrm{a}, \mathrm{A}}$ & $105 \%(\uparrow)$ \\
B_HRM & $0.224 \pm 0.001^{\mathrm{c}, \mathrm{B}}$ & $0.384 \pm 0.000^{\mathrm{c}, \mathrm{A}}$ & $71 \%(\uparrow)$ \\
B_HLM & $0.177 \pm 0.001^{\mathrm{e}, \mathrm{B}}$ & $0.386 \pm 0.001^{\mathrm{a}, \mathrm{b}, \mathrm{A}}$ & $117 \%(\uparrow)$ \\
\hline
\end{tabular}

All data are means \pm standard deviation $(n=6)$. a,b,c... - values with different superscripts in the same column for the same parameter are significantly different $(p \leq 0.05)$. ${ }^{\mathrm{A}, \mathrm{B}}$ - values with different superscripts in the same row are significantly different $(p \leq 0.05)$. Abbreviations: C: control; B HRP: biscuits with horseradish root pomace powder; B HLP: biscuits with horseradish leaf pomace powder; B_HRM: biscuits with horseradish root juice microcapsules; B_HLM: biscuits with horseradish leaf juice microcapsules. n.s.: change is statistically insignificant $(p>0.05)$. $\uparrow$ : Percentage increase after 180 -day storage. $\downarrow$ : Percentage decrease after 180-day storage.

of the biscuits without additives was 6.683 (sample C), whereas the $\mathrm{pH}$ of the biscuits containing horseradish products was significantly $(p \leq 0.05)$ lower compared to the control and ranged between 6.395 (B_HLP) and 6.476 (B_HRP). Since horseradish leaf products contained more organic acids (Table 2), their addition resulted in lowered $\mathrm{pH}$ of the biscuits (B HLP and B HLM). According to Ahmed \& Abozed [2015], organic acids may act as preservatives, thus improving the microbiological and physicochemical stability of the baked products. However, the $\mathrm{pH}$ of biscuits in the current research was higher than the values reported for crackers produced with Hibiscus sabdariffa by-products [Ahmed \& Abozed, 2015].

After 180-day storage, no significant $(p>0.05) \mathrm{pH}$ changes were observed in the biscuits (Table 4).

Water activity $\left(\mathrm{a}_{\mathrm{w}}\right)$ values of the control biscuits after baking were significantly higher $(p \leq 0.05)$ compared to the enriched biscuits (Table 4). The lowest water activity was measured in the biscuits with added horseradish leaves products (B_HLP and B_HLM) but these samples showed the highest increase in water activity after storage. Generally, there was an increase in water activity after 180-day storage, except for the control sample (sample $\mathrm{C}$ ). The water activity of the biscuits during storage had the same characteristics as that of commercial biscuits [Romani et al., 2016] and gluten-free biscuits with chestnut flour supplement [Paciulli et al., 2018], when it increased slightly during storage. 
TABLE 5. Colour parameters of biscuits enriched with horseradish products.

\begin{tabular}{l|c|c|c|c|c}
\hline Parameter & C & B_HRP & B_HLP & B_HRM & B_HLM \\
\hline $\mathrm{L}^{*}$ & $77.48 \pm 0.98^{\mathrm{a}}$ & $69.54 \pm 1.69^{\mathrm{b}}$ & $64.08 \pm 0.96^{\mathrm{c}}$ & $66.17 \pm 1.98^{\mathrm{b}, \mathrm{c}}$ & $64.04 \pm 2.01^{\mathrm{c}}$ \\
$\mathrm{a}^{*}$ & $1.53 \pm 0.22^{\mathrm{c}}$ & $2.70 \pm 0.14^{\mathrm{b}}$ & $3.69 \pm 0.65^{\mathrm{a}, \mathrm{b}}$ & $4.15 \pm 0.54^{\mathrm{a}}$ & $3.91 \pm 0.65^{\mathrm{a}, \mathrm{b}}$ \\
$\mathrm{b}^{*}$ & $22.16 \pm 1.04^{\mathrm{a}}$ & $22.53 \pm 1.94^{\mathrm{a}}$ & $22.33 \pm 1.59^{\mathrm{a}}$ & $21.52 \pm 1.29^{\mathrm{a}}$ & $23.81 \pm 1.04^{\mathrm{a}}$ \\
$\Delta \mathrm{E}$ & - & $8.24 \pm 0.74^{\mathrm{c}}$ & $13.77 \pm 1.45^{\mathrm{a}}$ & $11.90 \pm 1.01^{\mathrm{a}, \mathrm{b}}$ & $13.96 \pm 1.59^{\mathrm{a}}$ \\
Chroma & $22.16 \pm 1.22^{\mathrm{a}, \mathrm{b}}$ & $22.69 \pm 1.48^{\mathrm{a}}$ & $22.63 \pm 1.70^{\mathrm{a}}$ & $21.92 \pm 1.47^{\mathrm{a}, \mathrm{b}}$ & $24.12 \pm 1.57^{\mathrm{a}}$ \\
Hue angle $\left(^{\circ}\right)$ & $1.55 \pm 0.02^{\mathrm{a}}$ & $1.45 \pm 0.02^{\mathrm{b}}$ & $1.41 \pm 0.02^{\mathrm{b}, \mathrm{c}}$ & $1.38 \pm 0.02^{\mathrm{c}}$ & $1.41 \pm 0.03^{\mathrm{b}, \mathrm{c}}$ \\
$\Delta \mathrm{E}_{\mathrm{t}}$ & $2.06 \pm 0.15^{\mathrm{c}}$ & $2.69 \pm 0.24^{\mathrm{a}, \mathrm{b}}$ & $0.57 \pm 0.06^{\mathrm{d}}$ & $2.12 \pm 0.18^{\mathrm{c}}$ & $3.19 \pm 0.36^{\mathrm{a}}$ \\
\hline
\end{tabular}

Each measured value is the mean \pm standard deviation. $(n=20)$. a,b, $\ldots-$-values with different superscripts in the same row are significantly different $(p \leq 0.05)$. $\Delta \mathrm{E}$ shows difference between respective sample and control, $\Delta \mathrm{E}_{\mathrm{t}}$ is totatl colour difference between samples after 180-day storage compared with respective sample before storage. Abbreviations: C: control; B_HRP: biscuits with horseradish root pomace powder; B_HLP: biscuits with horseradish leaf pomace powder; B_HRM: biscuits with horseradish root juice microcapsules; B_HLM: biscuits with horseradish leaf juice microcapsules.

\section{Biscuit colour}

The colour of food is an important visual aspect that can either attract or deter consumers from a product, regardless of its true value. Therefore, the average values of colour parameters of the experimental biscuits after baking are reported in Table 5. The results showed that the addition of horseradish products significantly $(p \leq 0.05)$ increased the darkness and redness of the biscuits, but did not affect the blue-yellow tones. It may be affected by the transformation of phenolic compounds to quinones during heat treatment, which are subsequently converted to dark coloured melanins [Taranto et al., 2012]. Paciulli et al. [2018] also reported a similar trend in colour change upon baking when chestnut flour was added to gluten-free biscuits.

Pigments present in leaves increased the darkness of the experimental products. The darkest biscuits were obtained by adding horseradish leaf products (horseradish leaf pomace powder and microencapsulated horseradish leaf juice), which is indicated by the $\mathrm{L}^{*}$ values of the biscuit colour. The heat treatment caused changes of the natural pigments colour, and as a result of various reactions, the tone of the enriched biscuits turned brownish red, which is also visible from the results of $a^{*}$ values.

Higher $\mathrm{a}^{*}$ values were found for the biscuits with added horseradish root juice microcapsules (B_HRM), compared to the biscuits with horseradish root pomace. The differences between $a^{*}$ values are probably due to the use of maltodextrin as a wall material for the microcapsules. Similar observations have been made with the addition of cumin and caraway seeds and by-products [Sayed-Ahmad et al., 2018b], and chia seeds and cakes [Sayed-Ahmad et al., 2018a] to flour products.

The total colour difference $(\Delta \mathrm{E})$ indicates that the biggest differences compared to the control biscuits (sample $\mathrm{C}$ ) were observed in the biscuit samples enriched with horseradish leaf products (B_HLM and B_HLP). The $\triangle \mathrm{E}$ of B_HLM was by $9 \%$ higher than that of the control biscuits. The hue angle values indicate redness of the experimental biscuits, as the hue angle value is less than $10^{\circ}$ (Table 5).

In general, the enrichment of the biscuits with various horseradish products resulted in darker biscuits, which could be associated with non-enzymatic chemical reactions such as caramelization and browning reactions. Similar to the addition of grape marc extract to biscuits [Pasqualone et al., 2014], the colour of the experimental biscuits could be affected by the oxidation and degradation products of phenolics and chlorophyll compounds present in the horseradish products added.

Major colour changes after 180-day storage $\left(\Delta \mathrm{E}_{\mathrm{t}}\right.$, Table 5$)$ were observed in B_HLM biscuits, whereas no significant changes were observed in B_HLP samples. Additionally, it was the only sample with smaller $\Delta \mathrm{E}_{\mathrm{t}}$ than control $(\mathrm{C})$.

When assessing colour differences and changes in biscuit samples, it should be taken into account that the addition of natural plant products may cause changes in colour parameters due to the characteristic colour of these plant products, as well as mutual biochemical reactions.

\section{Bioaccessibility of TPC and antioxidant activity after biscuit digestion in vitro}

The high content and activity of phytochemicals in certain food ingredients does not always ensure high bioaccessibility and bioavailability during in vitro digestion. The results obtained in this study (Figure 1a) showed that TPC was significantly higher in all analysed biscuit samples after the digestion than before digestion, which is also consistent with other studies [Irakli et al., 2019; Szawara-Nowak et al., 2016; Zieliński et al., 2020].

The in vitro digestive process in the gastrointestinal tract involves the addition of enzymes and the adjustment of the $\mathrm{pH}$ at each stage according to the physiology of the human gastrointestinal tract. The effect of this process depends on the nature of the original sample. The metabolism and absorption of phenolic compounds usually depend on their physicochemical properties - basic structure, molecular size, degree of polymerization or glycosylation, solubility, as well as conjugation with other phenolic compounds [Carbonell-Capella et al., 2014].

Bioaccessibility indexes (PACs) after simulated gastric treatment were used in the study to evaluate the amounts of phenolics that are released from the relevant food matrix after digestion, making these compounds available for ab- 
A

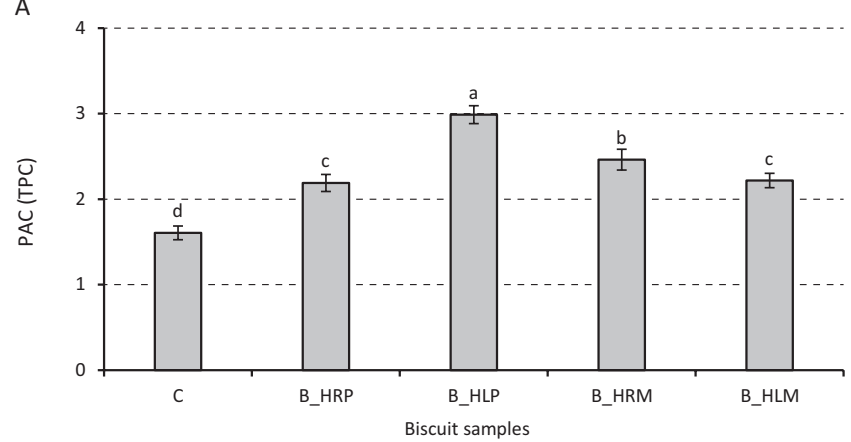

B
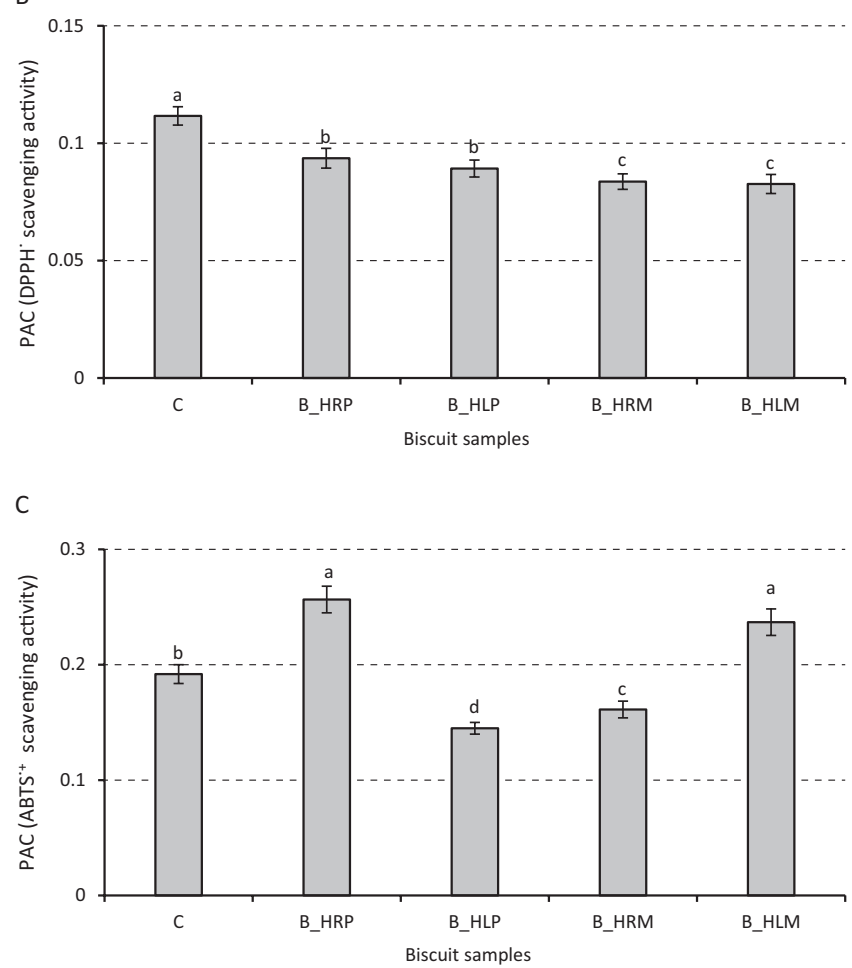

FIGURE 1. Bioaccessibility indexes (PACs) based on (A) TPC, (B) $\mathrm{DPPH}^{*}$ scavenging activity and $(\mathrm{C}) \mathrm{ABTS}^{*+}$ scavenging activity after biscuit in vitro digestion. $\mathrm{C}$ - control; B_HRP - biscuits with horseradish root pomace powder; B HLP - biscuits with horseradish leaf pomace powder; B_HRM - biscuits with horseradish root juice microcapsules; B_HLM - biscuits with horseradish leaf juice microcapsules; TPC - total phenolic content.

sorption through the gastrointestinal mucosa. Figure 1 shows the PACs based on the determination of TPC and antioxidant activity after digestion. In all biscuit samples, the PAC for TPC exceeded 1.6, showing a mean value of the phenolic bioavailability index of approximately 2.34. According to Zielinski et al. [2020], these values indicate high bioaccessibility. This can be explained by the fact that during digestion phenolics are released from cell wall matrices, as well as from their conjugated forms. There is also evidence in the literature that TPC of food matrices enriched with various natural substances increased after digestion [Irakli et al., 2019; Szawara-Nowak et al., 2016]. The highest PACs were observed for the biscuits with added horseradish leaf pomace powder (B_HLP), which were by $86 \%$ higher than these determined for the control biscuits.
Unfortunately, in all biscuit samples, the values of PAC based on the antioxidant activity were low (according to the criteria described by Zieliński et al. [2020]); i.e., 0.09 in the case of DPPH ${ }^{*}$ scavenging activity and 0.20 in the case of ABTS ${ }^{*}+$ scavenging activity (Figure 1b,c). This could indicate that some phenolic compounds with antioxidant properties in the food matrix, which are exposed to the in vitro digestion, interact with other compounds to form indigestible complexes [Jakobek, 2015], while other compounds may be released from their bound state. The highest PAC for $\mathrm{DPPH}^{*}$ scavenging activity was observed in the control biscuits. However, a higher PAC for $\mathrm{ABTS}^{\cdot+}$ scavenging activity was determined for the biscuits with added horseradish root pomace (B_HRP), which was by $33 \%$ higher than that of the control biscuits.

\section{CONCLUSION}

Pomace and microcapsules of horseradish root and leaves could potentially be used as the functional ingredients in foods due to their content of phenolic compounds with antioxidant activity. The addition of horseradish products to butter biscuits enriched the bakery product with phenolic compounds, as well as improved their antioxidant potential. Microencapsulated horseradish leaf juice was more effective in enriching the biscuits with bioactive compounds, thus opening up this raw material to new interesting applications in the food industry. The bioaccessibility indexes after biscuit digestion based on TPC indicated the high bioaccessibility of phenolic compounds from experimental products. Further research is required to optimise the functional recipe for horseradish-fortified flour confectionery, examining their potential health effects. It is also necessary to study the use of these raw materials in other products by assessing the properties and organoleptic attributes of these innovative functional raw materials that meet consumer expectations.

\section{ACKNOWLEDGEMENTS}

Authors acknowledge support of Dr. Ingmars Cinkmanis (Department of Chemistry, Faculty of Food Technology, Latvia University of Life Sciences and Technologies), as well as Engineer, Ph.D. Vanessa Durrieu (Laboratoire de Chimie Agro-industrielle, LCA, Université de Toulouse, INRAE, Toulouse, France). Authors also acknowledge a student of Jelgava secondary school No. 4 Anna Rusmane and her supervisor Aija Pridane for the co-operation within school research project, performing practical experiments.

\section{RESEARCH FUNDING}

This research was funded by the European Regional Development Fund Post-doctoral Research Support Program (project No.1.1.1.2/16/I/001), grant number 1.1.1.2./ VIAA/1/16/187.

\section{CONFLICT OF INTERESTS}

The authors declare no conflict of interest. 


\section{ORCID IDs}

L. Tomsone https://orcid.org/0000-0003-3879-3811

R. Galoburda https://orcid.org/0000-0002-5804-516X

Z. Kruma https://orcid.org/0000-0001-6123-1927

K. Majore https://orcid.org/0000-0001-8504-8473

\section{REFERENCES}

1. Agneta, R., Möllers, C., Rivelli, A.R. (2013). Horseradish (Armoracia rusticana), a neglected medical and condiment species with a relevant glucosinolate profile: a review. Genetic Resources and Crop Evolution, 60(7), 1923-1943.

https://doi.org/10.1007/s10722-013-0010-4

2. Ahmed, Z.S., Abozed, S.S. (2015). Functional and antioxidant properties of novel snack crackers incorporated with Hibiscus sabdariffa by-product. Journal of Advanced Research, 6(1), 79-87. https://doi.org/10.1016/j.jare.2014.07.002

3. Ajila, C.M., Aalami, M., Leelavathi, K., Rao, U.J.S.P. (2010). Mango peel powder: A potential source of antioxidant and dietary fiber in macaroni preparations. Innovative Food Science and Emerging Technologies, 11 (1), 219-224.

https://doi.org/10.1016/j.ifset.2009.10.004

4. Alminger, M., Aura, A.-M., Bohn, T., Dufour, C., El, S.N., Gomes, A., Karakaya, S., Martínez-Cuesta, M.C., McDougall, G.J., Requena, T., Santos, C.N. (2014). In vitro models for studying secondary plant metabolite digestion and bioaccessibility. Comprehensive Reviews in Food Science and Food Safety, 13, 413-436.

https://doi.org/10.1111/1541-4337.12081

5. AOAC (2020) Association of Official Analytical Chemists International: Official Methods of Analysis. AOAC 943.02-1943, pH of flour, potentiometric method [http://www.aoacofficialmethod. org/index.php?main_page=product_info\&products_id=937].

6. Belitz, H.D., Grosch, W., Schieberle, P. (2009). Food Chemistry. Springer Berlin Heidelberg. Retrieved from [https://books. google.co.in/books?id=xteiARU46SQC].

7. Calabrone, L., Larocca, M., Marzocco, S., Martelli, G. (2015). Total phenols and flavonoids content, antioxidant capacity and lipase inhibition of root and leaf horseradish (Armoracia rusticana) extracts. Food and Nutrition Sciences, 06(01), 64-74.

https://doi.org/10.4236/fns.2015.61008

8. Camponogara, C., Brum, E. da S., Belke, B.V., Brum, T.F., Jesus, R. da S., Piana, M., Bauermann, L. de F., Oliveira, S.M. (2020). Casearia decandra leaves present anti-inflammatory efficacy in a skin inflammation model in mice. Journal of Ethnopharmacology, 249, art. no. 112436.

https://doi.org/10.1016/j.jep.2019.112436

9. Carbonell-Capella, J.M., Buniowska, M., Barba, F.J., Esteve, M.J., Frígola, A. (2014). Analytical methods for determining bioavailability and bioaccessibility of bioactive compounds from fruits and vegetables: A review. Comprehensive Reviews in Food Science and Food Safety, 13(2), 155-171.

https://doi.org/10.1111/1541-4337.12049

10. Celep, E., İnan, Y., Akyüz, S., Yesilada, E. (2017). The bioaccessible phenolic profile and antioxidant potential of Hypericum perfoliatum L. after simulated human digestion. Industrial Crops and Products, 109, 717-723.

https://doi.org/10.1016/j.indcrop.2017.09.032
11. Dag, D., Kilercioglu, M., Oztop, M.H. (2017). Physical and chemical characteristics of encapsulated goldenberry (Physalis peruviana L.) juice powder. LWT - Food Science and Technology, 83, 86-94.

https://doi.org/10.1016/j.lwt.2017.05.007

12. Gayoso, L., Roxo, M., Cavero, Y.R., Calvo, I.M., Ansorena, D., Astiasarán, I., Wink, M. (2018). Bioaccessibility and biological activity of Melissa officinalis, Lavandula latifolia and Origanum vulgare extracts: Influence of an in vitro gastrointestinal digestion. Journal of Functional Foods, 44, 146-154.

https://doi.org/10.1016/j.jff.2018.03.003

13. Irakli, M., Katsantonis, D., Kleisiaris, F. (2015). Evaluation of quality attributes, nutraceutical components and antioxidant potential of wheat bread substituted with rice bran. Journal of Cereal Science, 65, 74-80.

https://doi.org/10.1016/j.jcs.2015.06.010

14. Irakli, M., Mygdalia, A., Chatzopoulou, P., Katsantonis, D. (2019). Impact of the combination of sourdough fermentation and hop extract addition on baking properties, antioxidant capacity and phenolics bioaccessibility of rice bran-enhanced bread. Food Chemistry, 285, 231-239.

https://doi.org/10.1016/j.foodchem.2019.01.145

15. ISO Standard 6496. (1999). Animal feeding stuffs — Determination of moisture and other volatile matter content.

16. Jakobek, L. (2015). Interactions of polyphenols with carbohydrates, lipids and proteins. Food Chemistry, 175, 556-567.

https://doi.org/10.1016/j.foodchem.2014.12.013

17. Kherbache, A., Senator, A., Laouicha, S., Al-Zoubi, R.M., Bouriche, H. (2020). Phytochemical analysis, antioxidant and antiinflammatory activities of Helichrysum stoechas (L.) Moench extracts. Biocatalysis and Agricultural Biotechnology, 29, art. no. 101826.

https://doi.org/10.1016/j.bcab.2020.101826

18. Kim, D.S., Lim, S.B. (2019). Subcritical water extraction of rutin from the aerial parts of common buckwheat. Journal of Supercritical Fluids, 152, art. no. 104561.

https://doi.org/10.1016/j.supflu.2019.104561

19. Kloucek, P., Smid, J., Frankova, A., Kokoska, L., Valterova, I., Pavela, R. (2012). Fast screening method for assessment of antimicrobial activity of essential oils in vapor phase. Food Research International, 47(2), 161-165. https://doi.org/10.1016/j.foodres.2011.04.044

20. Minekus, M., Alminger, M., Alvito, P., Ballance, S., Bohn, T., Bourlieu, C., Carrière, F., Boutrou, R., Corredig, M., Dupont, D., Dufour, C., Egger, L., Golding, M., Karakaya, S., Kirkhus, B., Le Feunteun, S., Lesmes, U., Macierzanka, A., Mackie, A., Marze, S., McClements, D.J., Ménard, O., Recio, I., Santos, C.N., Singh, R.P., Vegarud, G.E., Wickham, M.S.J., Weitschies, W., Brodkorb, A. (2014). A standardised static in vitro digestion method suitable for food - an international consensus. Food and Function, 5, 1113-1124.

https://doi.org/10.1039/C3F060702J

21. Mokdad, A., Mikšovská, J., Larsen, R.W. (2009). Photothermal studies of $\mathrm{CO}$ photodissociation from peroxidases from horseradish and soybean. Biochimica et Biophysica Acta - Proteins and Proteomics, 1794(11), 1558-1565. https://doi.org/10.1016/j.bbapap.2009.06.021

22. Moldovan, B., Iasko, B., David, L. (2016). Antioxidant activity and total phenolic content of some commercial fruit-flavoured 
yogurts. Studia Universitatis Babes-Bolyai Chemia, LXI(3, Tom 1), 101-108.

23. Naczk, M., Shahidi, F. (2004). Extraction and analysis of phenolics in food. Journal of Chromatography A, 1054(1-2), 95-111. https://doi.org/10.1016/S0021-9673(04)01409-8

24. Paciulli, M., Rinaldi, M., Cavazza, A., Ganino, T., Rodolfi, M., Chiancone, B., Chiavaro, E. (2018). Effect of chestnut flour supplementation on physico-chemical properties and oxidative stability of gluten-free biscuits during storage. LWT - Food Science and Technology, 98, 451-457.

https://doi.org/10.1016/j.Iwt.2018.09.002

25. Pasqualone, A., Bianco, A.M., Paradiso, V.M., Summo, C., Gambacorta, G., Caponio, F. (2014). Physico-chemical, sensory and volatile profiles of biscuits enriched with grape marc extract. Food Research International, 65(PC), 385-393. https://doi.org/10.1016/j.foodres.2014.07.014

26. Prieto, M.A., López, C.J., Simal-Gandara, J. (2019). Chapter Six - Glucosinolates: Molecular structure, breakdown, genetic, bioavailability, properties and healthy and adverse effects. Functional Food Ingredients from Plants, 90, 305-350. https://doi.org/10.1016/bs.afnr.2019.02.008

27. Re, R., Pellegrini, N., Proteggente, A., Pannala, A., Yang, M., Rice-Evans, C. (1999). Antioxidant activity applying an improved ABTS radical cation decolorization assay. Free Radical Biology and Medicine, 26(9-10), 1231-1237. https://doi.org/10.1016/S0891-5849(98)00315-3

28. Romani, S., Rocculi, P., Tappi, S., Dalla Rosa, M. (2016). Moisture adsorption behaviour of biscuit during storage investigated by using a new Dynamic Dewpoint method. Food Chemistry, 195, 97-103.

https://doi.org/10.1016/j.foodchem.2015.06.114

29. Sakač, M., Pestorić, M., Mandić, A., Mišan, A., Nedeljković, N., Jambrec, D., Jovanov, P., Lazić, V., Pezo, L., Sedej, I. (2016). Shelf-life prediction of gluten-free rice-buckwheat cookies. Journal of Cereal Science, 69, 336-343. https://doi.org/10.1016/j.jcs.2016.04.008

30. Sant'Anna, V., Gurak, P.D., Ferreira Marczak, L.D., Tessaro, I.C. (2013). Tracking bioactive compounds with colour changes in foods - A review. Dyes and Pigments, 98(3), 601-608. https://doi.org/10.1016/j.dyepig.2013.04.011

31. Sayed-Ahmad, B., Talou, T., Straumite, E., Sabovics, M., Kruma, Z., Saad, Z., Hijazi, A., Merah, O. (2018a). Evaluation of nutritional and technological attributes of whole wheat based bread fortified with Chia flour. Foods, 7(9), art. no. 135.

https://doi.org/10.3390/foods7090135

32. Sayed-Ahmad, B., Talou, T., Straumite, E., Sabovics, M., Kruma, Z., Saad, Z., Hijazi A., Merah, O. (2018b). Protein bread fortification with cumin and caraway seeds and by-product flour. Foods, 7(3), art no. 28.

https://doi.org/10.3390/foods7030028

33. Singleton, V.L., Orthofer, R., Lamuela-Raventós, R.M.B. (1999). [14] Analysis of total phenols and other oxidation substrates and antioxidants by means of Folin-Ciocalteu reagent. Methods in Enzymology, 299, 152-178.

https://doi.org/10.1016/S0076-6879(99)99017-1

34. Świeca, M., Gawlik-Dziki, U., Dziki, D., Baraniak, B. (2017). Wheat bread enriched with green coffee - In vitro bioaccessibil- ity and bioavailability of phenolics and antioxidant activity. Food Chemistry, 221, 1451-1457.

https://doi.org/10.1016/j.foodchem.2016.11.006

35. Szawara-Nowak, D., Bączek, N., Zieliński, H. (2016). Antioxidant capacity and bioaccessibility of buckwheat-enhanced wheat bread phenolics. Journal of Food Science and Technology, 53(1), 621-630.

https://doi.org/10.1007/s13197-015-2074-y

36. Taranto, F., Delvecchio, L.N., Mangini, G., Del Faro, L., Blanco, A., Pasqualone, A. (2012). Molecular and physico-chemical evaluation of enzymatic browning of whole meal and dough in a collection of tetraploid wheats. Journal of Cereal Science, 55(3), 405-414.

https://doi.org/10.1016/j.jcs.2012.02.005

37. Tomsone, L. (2015). Investigation of biologically active substances in horseradish and lovage. Ph.D. Thesis, Latvia University of Life Sciences and Technologies, Jelgava, Latvia, p. 148 (in Latvian).

38. Tomsone, L., Galoburda, R., Kruma, Z., Cinkmanis, I. (2020a). Characterization of dried horseradish leaves pomace: phenolic compounds profile and antioxidant capacity, content of organic acids, pigments and volatile compounds. European Food Research and Technology, 246(8), 1647-1660.

https://doi.org/10.1007/s00217-020-03521-z

39. Tomsone L., Galoburda, R., Kruma, Z., Durrieu, V., Cinkmanis, I. (2020b) Microencapsulation of horseradish (Armoracia rusticana L.) juice using spray-drying. Foods, 9(9), art. no. 1332. https://doi.org/10.3390/foods9091332

40. Villarino, C.B., Jayasena, V., Coorey, R., Chakrabarti-Bell, S., Johnson, S. (2014). The effects of bread-making process factors on Australian sweet lupin-wheat bread quality characteristics. International Journal of Food Science and Technology, 49(11), 2373-2381.

https://doi.org/10.1111/ijfs.12595

41. Yingyuen, P., Sukrong, S., Phisalaphong, M. (2020). Isolation, separation and purification of rutin from Banana leaves (Musa balbisiana). Industrial Crops and Products, 149(March), art. no. 112307. https://doi.org/10.1016/j.indcrop.2020.112307

42. Yu, L., Perret, J., Harris, M., Wilson, J., Haley, S. (2003). Antioxidant properties of bran extracts from "Akron" wheat grown at different locations. Journal of Agricultural and Food Chemistry, 51(6), 1566-1570. https://doi.org/10.1021/jf020950z

43. Zieliński, H., Del Castillo, M.D., Przygodzka, M., Ciesarova, Z., Kukurova, K., Zielińska, D. (2012). Changes in chemical composition and antioxidative properties of rye ginger cakes during their shelf-life. Food Chemistry, 135(4), 2965-2973. https://doi.org/10.1016/j.foodchem.2012.07.009

44. Zieliński, H., Szawara-Nowak, D., Wronkowska, M. (2020). Bioaccessibility of anti-AGEs activity, antioxidant capacity and phenolics from water biscuits prepared from fermented buckwheat flours. LWT - Food Science and Technology, 123, art. no. 109051. https://doi.org/10.1016/j.lwt.2020.109051

Submitted: 25 August 2020. Revised: 7 October and 4 November. Accepted: 6 November 2020. Published on-line: 9 December 2020. 